\title{
PRICE, OUTPUT, AND EXCHANGE RATE MOVEMENTS IN THE OPEN ECONOMY
}

\author{
Kent P. KIMBROUGH* \\ Duke University, Durham, NC 27706, USA
}

Since the advent of managed floating it has come to be accepted as a stylized fact that short-run deviations from purchasing power parity are both substantial and persistent. Two explanations of these deviations have been advanced in the literature. One emphasizes the role of changes in non-traded goods prices while the other views deviations from purchasing power parity as being due to sticky goods prices and slow adjustment of goods markets. This paper presents yet a third possible explanation of deviations from purchasing power parity - they may be necessary in order to facilitate the relative price changes that are required to maintain equilibrium in the face of unanticipated shocks. In addition, the issue of exchange rate ove shooting is addressed. Whereas the sticky price models view exchange rate overshooting and exciange rate volatility as symptoms of some fundamental disequilibrium, the perspective taken here is that these events are, in principle, compatible with a world in which all markets clear contiruously.

\section{Introduction}

Empirical evidence accumulated in the past several years of floating exchange rates indicates that deviations from purchasing power are both substantial and persistent. ${ }^{1}$ This is noted by Mussa (1979a) who argues that

'Whenever an exchange rate undergoes a substantial change over a short interval of time, this change is almost always associated with a significant divergence from relative purchasing power parity.'

Indeed, the economics profession now seems to be reaching consensus that while purchasing power parity is a viable description of the long-run relation between the exchange rate and national price levels, short-run deviations from purchasing power parity are a fact of life in a world of floating exchange rates.

It is not surprising that this emerging consensus on the empirical side has been accompanied by a similar consensus on the theoretical side. Acceptance

*I would like to thank George Tauchen, Ed Tower and an anonymous referee for their helpful comments.

${ }^{1}$ Recent studies by Frenkel (1981a), Isard (1977), and Kravis and Lipsey (1978) ail support this statement. The latter study, along with several others, appears in a recent issue oi the Journal of International Economics devoted solely to an examination of the purchasing power parity dortrine. Officer (1976) provides a thorough summary of the literature on purchasing power parity. 
of the view that flexible exchange rate models should be ca|able of explaining the sources of short-run deviations from purchasing pow parity while incorporating purchasing power parity as a long-run equ ilibrium condition is now widespread. Currently, there are two broad cl asses of models that are consistent with this widespread view of the appropt ate role of purchasing power parity in explaining exchange rate movements.

One class of models juilds on the work of Balassa (1964) and emphasizes the role of nontraded goods prices as at source of deviations from purchasing power parity. Proponents of this perspective point out that during the adjustment process following disturbances which result in a transitory discrepancy between actual and target wealth levels, the relative price of nontraded goods in terms of traded goods will deviate from its long-run value. This will resut in short-run deviations from purchasing power parity as indivicuais adjust their asset holdings to the target level. Throughout the adjustment process both goods and asset markets clear. The ultimate source of deviations from purchasing power parity is the slow adjustment of asset holdings to their target level through the current account. Models consistent with this perspective are Calvo and Rodriguez (1977), Flood (1977), Frenkel and Rodriguez (1980, sect. III), and Kimbrough (1980).

The second class of models allowing for short-run deviations from purchasing power parity while incorporating purchasing power parity as a long-run equilinrium condition was pioneered by Dornbusch (1976). ${ }^{2}$ Recent contributions hy Frenkel and Rodriguez (1980, section. II), Mussa (1977, 1979b) Nieharis (1977), and Wilson (1979) have elaborated, modifiec, and refined the Dornbusch framework. The perspective emerging from these models is that short-run deviations from purchasing power parity may be attributed to slow adjustment of goods markets. That is, temporary 'disequilibrium' in the gcodf market is seen as the fundamental source of deviations from purchasir 8 power parity. These models all incorporate slow adjustment of goods markets by imposing the assumption of price level 'stickyness'. When couple 1 with the fact that exchange rates are flexible, this assumption is seen to $b:$ at the heart of the deviations from purchasing power parity that csin be generated by these models. Presumably the justification for assuming price level stickyness is that time series studies show that exchange rates, like other asset prices, show little, if any, serial correlation, while nationai price levels, on the other hand, seem to be highly serially correlated.

Besides serving to gen rate short-run deviations from purchasing power parity, the assumption of price level stickyness has the added attraction of

\footnotetext{
${ }^{2}$ Dornbusch himself does not discuss the short-rua deviations from purchasing power parity stat characterize his model. However, others have argued that the inclusion of short-run dievations Irom purchasing pow $\mathrm{r}$ parity is a key aspect of the Dornbusch framework. See, for exartsple. Bitson (1979), Isard (19\%), and Mussa (1979b).
} 
being able to explain the fact that exchange rate movements in recent years appear to have been more volatile than justified by movements in their underlying determinants. Within the context of these sticky price models this has been rationalized by the exchange rate overshooting hypothesis. ${ }^{3}$ Dornbusch (1976) claims that exchange rate overshooing occurs because goods markets do not clear as rapidly as asset mariets. Exchange rate overshooting, like deviations from purchasing pover parity, is thus viewed as a disequilibrium phenomenon. The implication is that the volatility of exchinge rates in recent years is symptomatic of the failure of goods markets to clear.

The aim of this paper is twofold. First, it provides yet a third perspective which is consistent with the observations that short-run deviations from purchasing power parity are significant and that exchange rates are more volatile than national price levels in the short run. It is shown that even in a world without non-traded goods, and where both goods and asset markets clear $_{i}$ continuously, short-run deviations from purehasing power parity will occur if 'effective' information travels more rapidly in asset markets than in goods inarkets. ${ }^{4}$ Second, it also demonstrates that exchange rate overshooting does not require that goods markets clear more slowly than asset mairkets. Even with goods and asset markets clearing continuousiy exchange rate overshooting may occur, and hence the recent volatility of exchange rates is not necessarily indicative of goods market disequilibrium.

The wodel chosen to illustrate these points has features that are similar to both of "the broad classes of models that have already been discussed. Like those rodels emphasizing the role of non-traded goods in explaining deviaticins from purchasing power parity, the model presented in this paper is consistent with the view that such deviations are an equilibrium phenomenon. Like those models emphasizing sticky prices as the source of deviations from purchasing power parity, the model presented here is compat ble with exchange rate overshooting and is essentially an extension of the Mrndell (1963)-1leming (1962) framework which has been, and still is. popula in policy discussions. Not only are expectations introduced into tlie Munde 1-Fleming framework, as in the sticky price models cited earlier. but

\footnotetext{
${ }^{3}$ Bilso: (1978), Frenkel (1976), Frenkel and Mussa (1980), and Musss (1976) have ratioralized the volatile behavior of exchange rates by stressing the role of expectations of future events in the exch inge rate determination process. Meese and Singleton (1980) have recently prov ced an empirica ly implementable framework for jointly testing the rational expectations hypothesis and models if exchange rate determination. Their analysis subjects this argiement to critisism on the grounds that the revision of expzctations as individuals receive new information cannot lead to exchang rase variance in excess of the variance of the underlying determinants of the exchange rate.

${ }^{4}$ By 'iffective' information it is meant information which influences individual behavior. Informa:ion is 'ineffective' if it is received by an individual after he has already committed himself io a certain course of actiun. The source of the differential speed with which effective informat ion travels is, for purposes of illustration, assumed to be the existence of nominal wage contract: along the lines suggested by Fischer (1977) and Gray (1976).
} 
so are flexible prices (which guarantee goods narkets clear in both the short run and the long run) and a short-run aggregate supply function (or Phillips curve). One virtue of this approach, besides yielding results that are compatible with the observed regularities of exchange rate behavior, ${ }^{5}$ is that it accounts for fluclurations in output and, by implication, employment. This would seem to be an important extension as it allows for a discussion of stabilizatics policy in the open economy. ${ }^{6}$

The remainder of the paper is divided into three sections. Section 2 outlines the basic model. Section 3 discusses the effects of an unanticipated, but permanent, incirease in the domestic money supply on prices, output, and the exchange rate. It: is shown that the exihange rate may either overshoot or undershoot in rusponse to an unanticapated increase in the domestic money supply. Which of these results will occur is shown to depend on the reiative magnitudes of the income elasticity of sprending on domestic output, the insome elasticity of demand for money, ind the responsiveness of the trade accunt to cllianges in relative prices. It is also shown that in the short run the exchange rate will be more responsive to unanticipated monetary disturbances than the domestic price level. Therefore, unanticipated changes in the money supply will be associated with deviations from purchasing power parity. Reflection on the structure of the model suggests that this is a consequence of the fact that while today's expectations of future exchange rates affect aggregite behavior via interest rate parity, it is expectations formed yesterday about today's domestic price level that are relevant for determining the current output of donestic goods (through the Phillips curve). This point; out the fact that when compared to the sticky price models cited earlier, previously formed price level expectations have replaced sticky prices as the source of differences between the short-run and long-run response of the economy, and in particular the exchange rate, to unanticipated disturbances. The fourth, and final, section of the paper offers some concluding remairks.

\section{A macroeconomic model of a small oper economy'}

\subsection{The model}

Consider a small open economy facing a given world interest rate, $r_{f}^{*}$, on foreign currency dinnominated assets purchased at time $t$ and held until time $t+1$. With perfect capital mobility the domestic interest rate for the same holding period, $r_{t}$, rnust satisfy the interest rate parity condition

$$
r_{\mathrm{g}}=r_{\mathrm{g}}^{*}+x_{\mathrm{g}}
$$

${ }^{5} \mathrm{Sec}$ Mussa (1979a) for a detailed discussion of these regularities.

Several papers on the role of stabilization policy can be found in Fischer (1980).

The model presented in this section was developed independently of similar models employed bu Buter and Eaton (IS180), and Wallich and Gray (1980). 
where $x_{1}$ is the expected rate of depreciation of the domestic currency. Under the assumption that expectations are formed rationally

$$
x_{t}=E_{t} e_{t+1}-e_{t},
$$

where $e_{t}$ is the natural logarithm of the spot exchange rate at time $t$ and $E_{t} e_{t+1}$ is the expectation of the exchange rate at time $t+1$ conditioned on information available at time $t$. The information set at time $t$ is assumed to include knowledge of all current and past variables as well as knowledge of the structure of the economy. Combining these two conditions the interest rate parity condition becomes

$$
r_{t}=r_{t}^{*}+\left(E_{t} e_{t+1}-e_{t}\right)
$$

This is also the balance of payments equilibrium condition since any deviation from interest rate parity would trigger massive (infinite) capital flows.

Money market equilibrium requires that the supply of domestic money equal the demand, where the demand for money depends on income, the interest rate, and the price of domestic output. ${ }^{8}$ Assuming a Cagan type money demand function, the money market equilibrium condition is

$$
m_{t}-p_{t}=\phi y_{t}-\lambda r_{1}
$$

where $m_{t}, p_{t}$, and $y_{t}$ are the naturai logs of the domestic money supply, the price of domestic output, and income. The domestic money supply is generated by a stochastic process determined by the domestic monetary authorities. It will be useful for later purposes to rewrite (2) as

$$
r_{t}=(1 / \lambda)\left(\phi y_{t}-m_{t}+p_{t}\right)
$$

which is the domestic interest rate that is consistent with moncy market equilibrium.

Residents of the home country are assumed to consume two goods, one of which is produced domestically and one of which is imported. The home country produces only one good, some of which is exported to help pay for the country's imports. The home country is taken to be small in the world market for the good it imports, but is asstimed to be a major supplier of the good it produces domestically. Hence the price of domestic output is an endogenous variable.

\footnotetext{
${ }^{8}$ The price of domestic output is used as the deflat tor for domestic money for simplicity. The fundarnentals of the analysis would be unaltered if a weighted average of the prires of domestic and foreign output were used to deflate cash balances. In the remainder of the paper the terms domestic price level and price of domestic output will be used interchangetibly.
}

JMONE--B 
The demand for domestic output on the part of domestic residents depends on income, the domestic interest rate, and the relative price of the domestic good, $p_{z}-e_{t}-p_{t}^{*}$, where $p_{t}^{*}$ is the natural logarithm of the foreign currency price of foreign goods at time $t$. The price $p_{t}^{*}$ is taken as given since the home country is small in the market for the good it imports. Formally, the demand foi domestic output by dornestic residents (in levels) is ${ }^{9}$

$$
f\left(y_{i}, r_{t}, e_{t}+p_{t}^{*}-p_{t}, u_{1}\right)
$$

where $u_{11}$ reflects random elements influencing the demand for domestic output by domestic residents. The third term in (3) reflects the substitution of domestic residents toward domestic goods as their relative price falls. The demand for donnestic output by foreign residents (in levels) is given by ${ }^{10}$

$$
g\left(e_{t}+p_{t}^{*}-p_{1}, u_{2 t}\right)
$$

where $u_{2 t}$ captures the impact of random events on the foreign demand for domestic goods. The first torm in ( $\left.3^{\prime}\right)$ is again a substitution effect. The total demand for dornestic output (in levels) is the sum of (3) and ( $\left.3^{\prime}\right)$ and is thus given by

$$
h\left(y_{t}, r_{i} e_{t}+p_{t}^{*}-p_{t}, u_{1,}, u_{2 t}\right)=f\left(y_{t}, r_{t}, e_{t}+p_{t}^{*}-p_{t}, u_{1 t}\right)+g\left(e_{t}+p_{t}^{*}-r_{t}, u_{2}\right) .
$$

It is assumed. for simplicity, that $h(\cdot)$ is log linear, and therefore the natural logarithm of the demand for domestic output can be written as

$$
y_{t}^{d}=; y_{t}-\sigma r_{t}+\delta\left(e_{t}+p_{t}^{*}-p_{t}\right)+u_{t},
$$

where $u_{t}$ captures the effects of random events on the demand for domestic output (i.e., $u_{t}$ reflects boih $u_{1 t}$ and $u_{2 t}$ ). The parameter $\delta$ captures the substitution of both domestic and foreign residents towards domestic goods as their relative price falk. It is thus a measure of the responsiveness of the trade account to relative price thanges.

The supply of domestic output, $y_{i}^{s}$, is assumed to respond positively to unanticipated changes in the price of domestic output. The aggregate supply function, or Pliflips curve, is given by ${ }^{11}$

\footnotetext{
If should be noted that this specification of the demand function neglects wealth effects.

"Foreign income and interest. rates also influence the demand for domestic output by foreign residerts, but they have been suppressed by virtue of the small country asit mption. They may be viewed as being reflectied by the term $u_{2 p}$.

"Given tre aggregate suppiy' function (5), it is apparent that deviations of output from its natural level, $\bar{y}_{i}$, and deviations from purchasing power parity will not be serially correlated. However, time series data indicate that deviations of output from its natural level and deviations from purchasing power parity are both highly serially correlated. This can be accounted for by introducing terms reffecting lagged values of output into the aggregate supply function so that serially uncortelated forecast etrors will have long lasting effects. This can be justified on the basis of adjustmext costs as explained by Sargent (1979, chs. 13 and 16). This paper abstrac $s$ from this complication in order to focus on the impact effects of unanticipated disturbances.
} 


$$
y_{t}^{s}=\bar{y}_{t}+\theta\left(p_{t}-E_{t-1} p_{t}\right)+\varepsilon_{t},
$$

where $\bar{y}_{t}$ is the 'natural' level of domestic output, $E_{t-1} p_{t}$ is the expectation of the domestic price level conditioned on information available at time $t-1$, and $\varepsilon_{t}$ reflects random factors that influerse the output supply function.

It is important to note that there is ar: asymmetry in the information set that matters for expenditure and portfollo decisions on the one hand, and output (labor) supply decisions on th ; other. The interest rate parity condition, (1), assumes that the expected uture spot rate based on information available at time $t, E_{t} e_{t+1}$, is relevant when individuals make their expenditure and portfolio decisons. Hou ever, the aggregate supply function, (5), assumes that output depends on current period prices relative to their expected value conditioned on information available at time $t-1, E_{t-1} p_{t}$. Individuals, therefore, are assumed to tave full current information when making all asset market decisions, but not when making output (labor) supply decisions which are a crucial aspect of goods market behavior. That is, the model is asymmetric in that inforn ation, in effect, travels more rapidly in asset markets than in goods market . Having noted that the model is characterized by this asymmetry, it rem ins to justify it as being plausible. This can be done by considering the ggregate supply furction as being derived along the lines sketched by Fisch r (1977) and Gray (1976).

Suppose that at the start of each per od workers and firms negotiate and sign contracts in which workers agree tc supply a certain amount of labor at each nominal wage rate. That is, at the beginning of each period $t$ workers agree to a labor supply schedule. Since both parties are concerned with the real wage, the labor supply schedule fining firms will depend on the price level expected to prevail in period $t$. Corr racts are agreed to at the beginning of the period and hence the information set available for forming these expectations includes events through ariod $t-1$ only. As events unfold during period $t$ firms know the current rice of domestic goods and therefore can choose the point on the agreed to labor supply schedule that maximizes profits. This will generate an aggregate ilupply schedule of the type described by (5). ${ }^{2}$ It is also during period $t$ that workers make their expenditure and portfolio decisions. Hence the expected future spot rate that is important for decision making purposes is based on information available at time $t$. All markets clear continuously, but 'effective information travels more quickly in

\footnotetext{
${ }^{12}$ From this discussion it follows that the mag:itude of the elasticity of output supply with respect to unanticipated price changes, $\theta$, will dep nd on the elasticities of the labor supply and demand functions. It should also be noted that if ontracts were assumed to be staggered, as in Taylor (1980), price level expectations formed pr or to period $t-1$ would enter the aggregate supply function. This modification would hellp explain the cbserved serial correlation of deviations of output from its natural level and of deviations from purchasing power parity. Of course a more complete model would make bot contract length and the degree of indexing endogenous along the lines of Gray (1978) and Blichard (1980).
} 
asset markets than in goods markets due to the existence of labor contracting. ${ }^{\prime 3}$

\subsection{Solution of the model}

Goods market equilibrium requires that the dernand for domestic output equal the supply. This common equilibrium value is denoted $y_{t}$. Hence goods market equilibrium requires

$$
y_{i}^{d}=y_{t}=y_{i}^{s}
$$

Using (1) and (2') in (4) to eliminate the spot exchange rate $e_{t}$ and the domestic interest rate $y_{1}$, and imposing the equilibrium condition $y_{1}=y_{1}^{\mathrm{d}}$ yields

$$
y_{t}^{d}=(1 / A)\left\{C m_{t}+\delta\left(E_{t} e_{t+1}+r_{t}^{*}+p_{t}^{*}\right)-\cdot B p_{t}+u_{t}\right\}
$$

as the reduced form aggivgate demand function. This expression incorporates interest rate parity via (1) and money market equilibrium via (2'). It can be shown that

$$
\begin{aligned}
& A=1-\gamma+(\phi / \lambda)(\sigma+\delta), \\
& B=\delta+(1 / \lambda)(\sigma+\delta), \text { and } \\
& C=(1 / \lambda)(\sigma+\delta) .
\end{aligned}
$$

Equating aggregate supplv (5) and aggregate demand (7) yields

$$
\left.p_{t}=(1 / \theta A+B)\right)\left\{C m_{t}-A \ddot{y}_{t}+\theta A E_{t-1} p_{t}+\delta\left(E_{t} e_{t+1}+r_{t}^{*}+p_{t}^{*}\right)+u_{t}-A \varepsilon_{t}\right\}
$$

\footnotetext{
${ }^{4}$ Barro (1977) argues that if labor contracting is optimal output and employment will not respond to unanticipated, but contempiraneously observed, monetary shocks. However, Waldo 11941 has recently employed an explicit optimization framework to show that Barro's conclusion holds only under certain conditions - for exaruple, risk ncutrality on the part of both entrepreneurs and workers. Under other reasonable conditions the existence of optimal Ibbor contracts can be consisten' with an aggregate supply function like (5). For example, Waldo demonstrates that if entreprenturs are risk neutral, workers are risk averse, and the labor supply curve is backward bending an aggregate supply function like (5) will be the outcome of optimal laber contracting This is one set of microeconomic assumptions which is compatible with the model cmployed in this paper. It is consistent with the aggregate supply function (5) and with the fact that agents have cuntenporaneous money supply information [as implies by (1)], and thus with the stylized face that information travels inore rapidly iri asset markets than in goods markets.
} 
as the equilibrium domestic price level at time $t$. Using (8) in (5) yields

$$
\begin{aligned}
y_{t}= & (B / \theta A+B))\left(\bar{y}_{t}+\varepsilon_{t}-\theta E_{t-1} p_{t}\right)+\theta /(\theta A+B) \\
& \times\left\{C m_{t}+\delta\left(E_{t} e_{t+1}+r_{t}^{*}+p_{t}^{*}\right)+u_{t}\right\}
\end{aligned}
$$

as the equilibrium level of domestic output. Using (8) and (9) in (2') yields an expression for the equilibrium domestic interest rate:

$$
\begin{aligned}
r_{t}= & \frac{1}{\lambda(\theta A+B)}\left\{(\phi B-A)\left(\bar{y}_{t}+\varepsilon_{t}-\theta E_{t-1} p_{t}\right)\right. \\
& \left.-[\theta(1-\gamma)+\delta] m_{t}+(1+\phi \theta)\left[\delta\left(E_{t} e_{t+1}+r_{t}^{*}+p_{t}^{*}\right)+u_{t}\right]\right\} .
\end{aligned}
$$

Finally, using (10) in (1) the equilibrium exchange rate at time $t$ is given by

$$
\begin{aligned}
e_{t}= & D\left(E_{t} e_{t+1}+r_{t}^{*}\right)-\frac{1}{\lambda(\theta A+B)}\left\{( \phi B - A ) \left(\bar{y}_{t}\right.\right. \\
& \left.\left.+\varepsilon_{t}-\theta E_{t-1} p_{t}\right)-[\theta(1-\gamma)+\delta] m_{t}+(1+\phi \theta)\left(\delta p_{t}^{*}+u_{t}\right)\right\},
\end{aligned}
$$

where

$$
D=1-\frac{\delta(1+\phi \theta)}{\lambda(\theta A+B)}=\frac{\lambda[\theta(1-\gamma)+\delta]+\sigma(1+\phi \theta)}{\lambda[\theta(1-\gamma)+\delta]+(\sigma+\delta)(1+\phi \theta)} .
$$

It should be noted that $0<D<1$.

Expressions (8)-(11) show the equilibrium values of the current period endogenous variables $p_{t}, y_{t}, r_{t}$, and $e_{t}$ as functions of $E_{t-1} p_{t}, E_{t} e_{t+1}$, and other variables. The price level expected to prevail at time $t$ conditional on information available at time $t-1, E_{t-1} p_{t}$, is predetermined at time $t$, but the expected future spot rate conditional on information available at time $t$. $E_{t} e_{t+1}$, is not. Hence in order to close the model an expression for the expected future spot rate must be obtained.

Taking expectations of (8) conditional on information available at time $t-1$ yields

$$
E_{t-1} p_{t}=\frac{1}{B} E_{t-1}\left\{C m_{t}-A \bar{y}_{t}+\delta\left(r_{t}^{*}+p_{t}^{*}\right)+u_{t}-A \varepsilon_{t}\right\}+\frac{\delta}{B} E_{t-1} \epsilon_{t+1}
$$

since $E_{t-1}\left(E_{t} e_{t+1}\right)=E_{t-1} e_{t+1}$ by the law of iterated projections. Using (12) in (11) it can be seen that

$$
e_{t}=D E_{t} e_{t+1}+\frac{\delta \theta(\phi B-A)}{B \lambda(\theta A+B)} \cdot E_{t-1} e_{t+1}+v_{t}+E_{t-1}=
$$


where

$$
\begin{aligned}
r_{t}= & D r_{t}^{*}-\frac{1}{\lambda(\theta A+B}\left\{(\phi E-A)\left(\bar{y}_{t}+\varepsilon_{t}\right)\right. \\
& \left.-[\theta(1-\gamma)+\delta] n_{t}+(1+\phi \theta)\left(\delta p_{t}^{*}+u_{t}\right)\right\}, \text { and } \\
\xi_{t}= & \frac{\theta(\phi B-A)}{B \lambda(\theta A+B)}\left\{C v_{t}-A \bar{y}_{t}+\delta\left(r_{t}^{*}+p_{t}^{*}\right)+u_{t}-A \varepsilon_{t}\right\} .
\end{aligned}
$$

As expression (13) shows, xpectations formed prior to time $t$ are relevant for determining the equilibrivm exchange rate at time $t$. The reason for this is that expectations of the price level at time $t$ conditioned on information available at time $t-1$ arc relevant for determining current output, and the latser is one of the underly ing determinants of the equilibrium exchange rate.

From (13) it is clear that the general expression for the equilibrium exchange rate at time $t+i$ is

$$
\mathbb{A}_{t+i}=D E_{t+i} e_{t+i+1}+\frac{\delta \theta(\phi B-A)}{B \lambda(\theta A+B)} E_{t+i-1} e_{t+i+1}+v_{t+i}+E_{t+i-1} \xi_{t+i} .
$$

Setting $i=1$ in this expression and taking expectations at time $t$ yields

$$
\begin{aligned}
& E_{t} e_{t+1}=\mu E_{t} e_{t+2}+E_{t} \eta_{t+1}, \text { where } \\
& \mu=D+\frac{\delta \theta\left(\phi B-\lambda_{i} ;\right.}{B \lambda(\theta A+B)}=\frac{\sigma+\lambda \delta}{\sigma+(1+\lambda) \delta}<1, \text { and } \\
& \eta_{t+1}=v_{t+1}+b_{t+1}
\end{aligned}
$$

Using the definitions of $v$ and $\xi$ it can be be shown that

$$
\eta_{t+1}=(1 / B \lambda)\left\{\delta m_{t}+(\sigma+\lambda \delta) r_{t}^{*}+[(1-\gamma)-\delta]\left(\bar{y}_{t}+\varepsilon_{t}\right)-\delta p_{t}^{*}-u_{t}\right\} .
$$

Expression (14) is a first order difference equation and can be solved to yield the forward looking solution for the expected future spot rate

$$
E_{i} e_{i+1}=\sum_{i=0}^{\infty} \mu^{i} E_{1} \eta_{1+1+i}
$$

In a similar manner it can be shown that

$$
E_{t-i} e_{t+1}=\sum_{i=0}^{\infty} \mu^{i} E_{t-1} \eta_{t+1+i}
$$


Given $E_{t-1} p_{t}$ and $E_{t-1} e_{t+1}$, expressions (8)-(11) and (15) provide a complete solution for the contemporaneously determined variables $p_{t}, y_{t}, r_{t}$, $e_{t}$, and $E_{t} e_{t+1}$.

\section{The effects of unanticipated money}

In this section the effects of an unanticipated increase in the domestic money supply at time $t$ on prices, output, the domestic interest rate, and the exchange rate are studied. It is assumed that domestic residents, as of time $t$, expect this increase in the money supply to be permanent, and that the realized values of all other exogenous variables equal their expected values as of time $t-1$. The key questions to be answered are whether or not an unanticipated increase in the money supply will be accompanied by (i) deviations from purchasing power parity, and (ii) exchangt rate overshooting. Regarding the latter, it has been pointed out by Flood (1979) that exchange rate overshooting can be defined only relevant to some benchmark change in the exchange rate. In this paper overshooting is said to occur if the response of the exchange rate to an unanticipated disturbance is greater than its response to a similar anticipated disturbance. In response to monetary disturbances, it can be shown that the elasticity of the exchange rate to an anticipated, permanent monetary disturbarce is unity. ${ }^{14}$ This is the benchmark against which overshooting is defined in this section.

\subsection{Exchange rate movements}

From the assumptions mentioned in the preceding paragraph, it can be shown using (13) that the unexpected change in the exchange rate due to an unanticipated, permanent monetary expansion is

$$
\Delta^{u} e_{t}=D\left(E_{t} e_{t+1}-E_{t-1} e_{t+1}\right)+\frac{\theta(1-\gamma)+\delta}{\lambda(\theta A+B)} \Delta^{u} m_{t}
$$

where the operator $A^{u}$ is defined so that $A^{u} z_{t}=z_{t}-E_{t-1} z_{t}$. Expression (17) shows that the unanticipated change in the exchange rate results from two sources. First, there is the change in expectations concerning future events which is summarized by the change in the expected spot rate at time $t+1$ between periods $t-1$ and $t$. Second, the unexpected change in the domestic money supply directly affects the level of economic activity at time $i$, through the Phillips curve, and hence directly influences the equilibrium exchange rate at time $t$. This is shown by the second term in (17). Both of these effects are similar in nature in that they reflect the change in the information set between periods $t-1$ and $t$. That is, the unexpected change in the exchange

\footnotetext{
${ }^{14}$ This can be seen from (8) (12), (15), and (16).
} 
rate is a consequence of 'news' received by market participants between periods $t-1$ and $t .^{15}$

However, from (15) and (16) it can be seen that the change in the expected exchange rate at time $t+1$ is given by

$$
E_{t} e_{t+1}-E_{t-1} e_{t+1}=\sum_{i=0}^{\infty} \mu^{i}\left(E_{t} \eta_{t+1+i}-E_{t-1} \eta_{t+1+i}\right)
$$

Using the definition of $\eta$ it can be shown that $E_{t} \eta_{t+1+i}-E_{t-1} \eta_{t+1+i}=$ $(\delta / B i) d^{4} m_{t}$. From this and (18) it follows that $E_{t} e_{t+1}-E_{t-1} e_{t+1}=\Delta^{u} m$. Using this in (17) yields

$$
\frac{A^{4} e_{t}}{A^{4} m_{t}}=1+\frac{\theta[(1-\eta)-(b \delta]}{\lambda(\theta A+B)}
$$

Therefore the exchange rate over- or undershoots as ${ }^{16}$

$$
(1-\eta)-\phi i \xi 0 \text {. }
$$

This condition can be interpreted as follows: Suppose that the exchange rate neither overshoots nor undershoots following an unanticipated, permanent monetary expansion. That is, suppose that $\Delta^{u} e_{t} / \Delta^{u} m_{t}=1$, or equivalently that

$$
\Delta^{\prime \prime} e_{\imath}=\Delta^{\prime \prime} m_{1}
$$

This, together with the just noted fact that $E_{t} e_{t+1}-E_{t-1} e_{t+1}=\Delta^{u} m_{t}$, implies that the expected rate of depreciation of the domestic currency, $x_{t}$, remains unchanged when the exchange rate neither over- or undershoots. ${ }^{17}$ In conjunction with the interest rate parity conditions, (1), this implies that $\Delta^{u} r_{\text {, }}$ $=0$. Using (4), and the fact that $y_{t}^{d}=y_{t}$ in equilibrium, this means that when $\Delta^{w} e_{t} \Delta^{n} m_{1}=1$ there will be an excess supply of domestic goods equal to ${ }^{18}$

$$
(1-\gamma)\left(\Delta^{u} y_{u}\left(\Delta^{u} m_{t}\right)-\delta\left(1-\Delta^{u} p_{t} / \Delta^{u} m_{t}\right)\right.
$$

\footnotetext{
isee Frenkel (1981b), Frenkel and Mussa (1980), and Mussa (1979a, 1979b) for discussions of the role of 'news' in determining unexpected changes in the exchange rate.

${ }^{16} T$ this is the same as the criterion for over- or undershooting that Dornbusch (1976) obtains in bis appendix where a Phillips curve of sorts is introduced, but the assumption of sticky prices is maintained.

inecall that $x_{t}=E_{t} e_{t+1}-e_{t}$. Hence the change in the expected rate of depreciacion accosapanyine an unantisipated monetary expansion, $\Delta^{4} x_{t}=x_{1}-E_{t-1} x_{t}$, is given by $\Delta^{u} x_{t}=E_{t} e_{1+1}$ $\left.-E_{z}-E_{t}-\frac{1}{\left(E_{t} E_{s}+1\right.}-E_{t}\right)$. Using the law of interated projections and rearranging this becomes $\Delta^{4} x_{t}$ $\therefore E_{z} E_{t}-\varepsilon-E_{t-1} z_{t+1}-\left(e_{1}-E_{t-1} e_{t}\right)$. From the fact that $E_{t} e_{t+1}-E_{t-1} e_{t+\varepsilon}=\Delta^{n} m_{t}$ and the definition

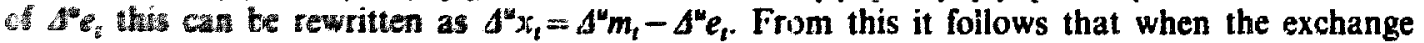
wate neither over- on undershoots $\Delta^{\text {st }} x_{1}=0$.

"Solutions for $d^{*} y_{y} \Delta^{*} m$, and $d^{u} p_{v} / \Delta^{\prime \prime} m_{1}$ are given in expressions (21) and (20).
} 
However, from (2) it can be seen that money market equilibriun requires that

$$
1-\left(\Delta^{u} p_{t} / \Delta^{u} m_{t}\right)=\phi\left(\Delta^{u} y_{t} / \Delta^{u} m_{t}\right)
$$

in this instance. Using this to eliminate $\Delta^{u} \eta_{t} / \Delta^{u} m_{t}$ from the preceding expression yields

$$
[(1-\gamma)-\phi \delta]\left(\Delta^{u} y_{t} / \Delta^{u} m_{t}\right)
$$

as the excess supply of domestic goods that will result from an unanticipated. permanent monetary expansion if the exchange rate neither overshoots or undershoots. Therefore, if $(1-\gamma)-\phi \delta>0$ there will be an excess supply of domestic goods when $\Delta^{u} e_{t} / \Delta^{1} m_{l}=1 .{ }^{19}$ This excess supply of domestic goods will put pressure on the exchange rate to depreciate thus reducing the relative price of domestic goors and eliminating the excess supply. Hence if $(1-\gamma)-\phi>0$ the exchange rate must overshoot to maintain goods market equilibrium. On the other hand, if $(1-\gamma)-\phi \delta<0$ there will be an excess demand for domestic goods when $\Delta^{u} e_{t} / \Delta^{u} m_{t}=1$, and thus the exchange rate must undershoot to maintain goods market equilibrium.

It should be noted from (19) that the parameters $\theta, \lambda$, and $\sigma$ play no role in determining whither or not the exchange rate over- or undershoots, but they do influence the magnitude by which the exchange rate over- or undershoots. The more responsive output is to unanticipated changes in the price of domestic cutput, i.e., the larger $\theta$, the greater the extent of over- or undershooting. This follows from the fact that the larger $\theta$ the larger will be the excess supply or demand for domestic output if $\Delta^{u} e_{t} / \Delta^{u} m_{t}=1$, and hence the greater must be the over- or undershooting of the exchange rate in order to maintain equilibrium. On the other hand, the larger $\lambda$ or $\sigma$ the more changes in the domestic interest rate associated with changes in the exchange rate will work to maintain equilibrium in the goods and money markets, and hence the less the exchange rate must over- or undershoot.

It can also be seen from (19) that exchange rate overshooting is more likely the smaller the income elasticity of spending on domestic output, $\gamma$, the smaller the income elasticity of demand for money, $\phi$, and the less sensitive the trade account is to changes in the relative price of domestic output as shown by $\delta$. It should also be noted that by using the definitions of the reduced form coefficients $A$ and $B,(19)$ can be rewritten as

$$
\frac{\Delta^{u} e_{t}}{\Delta^{u} m_{1}}=\frac{\theta[(1-\gamma)(1+\lambda)+\phi \sigma]+\lambda B}{\lambda(\theta A+B)}>0 .
$$

${ }^{19}$ This follows from the fact that $A^{4} y_{t} / \Delta^{4} n_{t}>0$ as shown by (21). 
This implies that the domestic currency will depreciate relative to its expected value, $E_{t-1} e_{t}$, in response to an unantic ated domestic monetary expansion. ${ }^{20}$

The key insight to be gained from all of this is that exchange rate overshooting, or undershooting for that matter, can occur in order to maintain goods market equilibrium. This is in direct contrast to the sticky price models cited earlier where exchange rate overshooting was viewed as a result of the failure of goods markets to clear. The upshot is that to the extent that exchange rate overshooting has contributed to the recent volatility of exchange rates, it does not necessarily indicate the presence of some undeslying 'divequilibrium'. Instead, exchange rate overshooting may be required in order to maintain equilibrium

\subsection{Prices, output, and the interest rate}

To obtain the unexpected change in the price of domestic output, subtract $E_{t}, p_{t}$ from both sides of (8), and use (12) in the resulting expression to obtain

$$
\left.\Delta^{\prime \prime} p_{t}=(1 / \theta A+B)\right)\left\{C \Delta^{\prime \prime} m_{t}+\delta\left(E_{t} e_{t+1}-E_{t-1} e_{t+1}\right)\right\} .
$$

Using the fact that $E_{t} e_{t+1}-E_{t-1} e_{t+1}=\Delta^{u} m_{t}$ this yields

$$
\Delta^{\prime \prime} p_{v} \Delta^{\prime \prime} m_{i}=B /(\theta A+B)<1 .
$$

From the output supply function it follows that

$$
\Delta^{\prime \prime} y_{v} / \Delta^{\prime \prime} m_{t}=\frac{\theta B}{(\theta A+B)}>0
$$

gives the response of domestic output to an unanticipated monetary diturbance. An unanticipated expansion of the domestic money supply raises the price of domesic output above its expected value and leads to an unanticipated expansion of domestic output.

From (1) it can be shown that $\Delta^{u} r_{t} / \Delta^{u} m_{t}=1-\Delta^{u} e_{t} / \Delta^{u} m_{t}$, and using (19) it follows that

$$
\Delta^{\prime \prime} r_{i} \Delta^{u} m_{1}=-\theta[(1-\gamma)-\phi \delta] / \lambda(\theta A+B) .
$$

Therefore, an unanticipated nonetary expansion causes the domestic interest rate to be below or above its expected value as the exchange rate over-or undiershoot:

\footnotetext{
It This ressil? depends on the reasonable assumption that $\gamma$ is not 'tog' large.
} 
At this point it is possible to present an alternative explanation of the criterion for exchange rate over- or undershooting. ${ }^{21}$ From $\left(2^{\prime}\right)$ it can be seen that the unanticipated change in the domestic interest rate due to an unanticipated monetary disturbance is

$$
\Delta^{u} r_{t} / \Delta^{u} m_{t}=\left((-1 / \lambda)\left(1-\phi\left(\Delta^{u} y_{t} / \Delta^{u} m_{t}\right)-\Delta^{u} p_{t} / \Delta^{u} m_{t}\right) .\right.
$$

The expression in parentheses is the excess supply of money at the expected domestic interest rate, $E_{t-1} r_{t}$. that arises from an unanticipated monetary disturbance. Hence if there is an excess supply of money at the expected domestic interest, an unanticipated increase in the money supply will cause the domestic interest rate to fall below its expected value in order to clear the money market. Similarly, if there is an excess demand for money at the expected domestic interest rate, an unanticipated increase in the money supply will cause the domestic interest rate to rise above its expected value. Substituting (20) and (21) into (23), expression (22) can be obtained. According to this interpretation, the expression $(1-\gamma)-\phi \delta$ indicates whether an unanticipated monetary expansion will lead to an excess supply (if positive) or an excess demand (if negative) for money at the expected domestic interest rate. From (1) it can be shown that

$$
\frac{\Delta^{u} e_{t}}{\Delta^{u} m_{t}}=\frac{E_{t} e_{t+1}-E_{t-1} e_{t+1}}{\Delta^{u} m_{t}}-\frac{\Delta^{u} r_{t}}{\Delta^{u} m_{t}} .
$$

It was shown earlier that the first term in the preceeding expression will equal unity. Hence it follows that $\Delta^{u} e_{t} / \Delta^{u} m_{t}=1-\Delta^{u} r_{t} / \Delta^{u} m_{t}$. Therefore, in order to maintain interest rate parity the exchange rate will over- or undershoot in response to an unanticipated monetary expansion as there is an excess supply of or demand for money at the expected domestic interest rate.

This ard the earlier explanation of the exchange rate over.- or undershooting criterion help to illustrate a general point about exchange rate determination. That is, the equilibrium exchange rate is determined as part of the general equilibrium of the system. It is a matter of emphasis. not of substance, whether one chooses to stress the connection between goods market equilibrium and the exchange rate [as the explanation immediately following (19) does] or the connection between money market equilibrium and the exchange rate (as the explanation just presented does).

\subsection{Deviations from purchasing power parity}

Besides the issue of overshooting, the other major question posed at the

\footnotetext{
${ }^{21}$ This explanation is simiar to that accompanying the model outlined in the appendix to Dornbusch (1976).
} 
start of this section was whether or not unanticipated monetary disturbances will be accompanied by deviations from purchasing power parity. For sach deviations to occur unanticipated monetary disturbances must alter relative prices. That is, an unanticipated monetary disturbance must result in a relative price of domestic goods in period $t, p_{t}-e_{t}-p_{t}^{*}$, that differs from its expected value as of period $t-1, E_{t-1}\left(p_{t}-e_{t}-p_{t}^{*}\right)$. The question of whether or not deviations from purchasing power parity will occur, can thus be answered by considering what would happen if an unanticipated increase in the money supply occurred and the relative price of domestic goods remained at its previously expected value, $E_{t-1}\left(p_{t}-e_{t}-p_{t}^{*}\right)$.

Suppose that the money supply was to increase unexpectedly by $d^{u} m_{i}$ in period $t$, and that this was accempanied by an unanticipated increase in the price of domestic output equal to that given by (20). Given that the price of foreign output has been assumed to equal its expected value (i.e., $p_{t}^{*}=E_{t-1} p_{t}^{*}$ has been atsumed), the relative price of domestic goods will equal its expected value as of period $t-1$ only if the unanticipated exchange rate change equals the unanticipated increase in the price of domestic output. That is, for $p_{t}-e_{t}-p_{t}^{*}=E_{t-1}\left(p_{t}-e_{t}-p_{t}^{*}\right)$ to occur following an unanticipated incraste in the domestic money supply, it must be true that

$$
\Delta^{\prime \prime} e_{t} \Delta^{\prime \prime} m_{t}=\Delta^{u} p_{t} / \Delta^{u} m_{t}
$$

However, when this occurs, and when the unanticipated increase in the price of domestic goods is given by (20), individuals will anticipate a depreciation of the exchange rate between periods $t$ and $t+1$ since

$$
\Delta^{\prime \prime} e_{v} \Delta^{\prime \prime} m_{\imath}<1,
$$

and it is known that eventually the exchange rate will depreciate by the same proportion as the increase in the domestic money supply. This implies that in response to an unanticipated increase in the domestic money supply, maintenance of interest rate parity requires that the domestic interest rate exceed its expected value when the relative price of domestic goods remains at its expected value. This unanticipated rise in the domestic interest rate, coupled with the unanticipated increase in domestic output (due to the unanticipated rise in the price of domestic output) implies an excess supply of domest: output will exist if the relative price of domestic goods remains at its expected value. Therefore, in order to maintain equilibrium, an unanticipated increase in the domestic money supply must be accompanied by an unanticipated fall in the relative price of domestic goods. That is, deviaticons from purchasing power parity must occur. It is important to note that these deviations are necessary in order to maintain equilibrium in the face of unarticipated monetary disturbances - they are not a result of 
disequilibrium as in the sticky price models cited in the introduction. Deviations from purchasing power parity would not occur if price level expectations based on information available at time $t$, rather than $t-1$, where relevant for output (labor) supply decisions. Therefore, in this model. deviations from purchasing power parity can be attributed to the fact that information travels more rapidly in asset markets than in goods markets.

Formally, it can be shown that deviations from purchasing power parity will be associated with unanticipated monetary disturbances by subtracting (20) from (19) to obtain ${ }^{22}$

$$
\frac{\Delta^{u} e_{t}-\Delta^{u} p_{t}}{\Delta^{u} m_{t}}=\frac{\theta[(1-\gamma)(1+\lambda)+\phi \sigma]}{\lambda(\theta A+B)}>0 .
$$

As (24) shows, deviations from purchasing power parity will occur in response to unanticipated monetary disturbances and, in a quantitative sense, are a consequence of the fact that in the short run exchange rates are more responsive to unanticipated disturbances than are goods prices. This is in accord with the empirical evidence which shows that exchange rates are more volatile than national price levels.

\section{Conclusion}

Since the advent of the current regime of managed floating, it has corme to be accepted as a stylized fact that while purchasing power parity is a reasonable characterization of the long-run behavior of exchange rates, shortrun deviations from purchasing power parity are both substantial and persistent. Recent work in international economics has presented two vantage points from which to view these deviations. One builds on the work of Balassa (1964) and emphasizes the role of changes in non-traded goods prices as a source of deviations from purchasing power parity. The other originated with the work of Dornbusch (1976) and views deviations from purchasing power parity as a disequilibrium phenomenon associated with sticky prices and slow adjustment of goods markets.

This paper has presented yet a third perspective from which to view shortrun deviations from purchasing power parity. A simple open economy macroeconomic model along the lines of the Mundell-Fleming model was presented; the main innovations being the introduction of flexible prices and

\footnotetext{
${ }^{22}$ Note that even though Dornbusch (1976) obtains the same criterion as that derived here for over- or undershooting of the exchange rate, in his model the exchange rate must respend more than the price level in the short run due to the assumption of sticky prices. Exp-ession (24) is positive because of the assumption mentioned in footnote 16 that $y$ is not 'to' large. This expression corresponds to using the price ratio that would prevail without the monetary shock as the benchmark against which deviations from purchasing power are measured. Thi: follows from the fact that I have assumed no other unexpected shocks occur.
} 
a rational expeciations aggregate supply function. Within the context of this model, it was shown that unanticipated, permanent monetary disturbances will be astiociated with deviations from purchasing power parity. The source of these deviations from purchasing power parity was shown to lie in the fact that 'effective' information travels more rapidly in asset markets ihan in goccis markets. In contrast to the sticky price models which view deviations írom purchasing power parity as a disequilibrium phenomenon, the model presented in this paper takes the view that deviations from purchasing power parity can reflect relative price changes which are required to maintain equilibrium in the face of unanticipated disturbances.

In addition to intruducing a third perspective from which to view deviations from purchasing power parity, this paper also has implications for the over-shooting hypothesis which has been widely discussed as a source of exchange rate volatility. It was shown that either over- or undershooting may occur in response to an unanticipated, permanent increase in the domesic money supply, and that exchange rate overshooting is more likely the smaller the income elasticities of spending on domestic output and the demand for money, and the less responsive the trade account to relative price changes. Again, the results presented here are in stark contrast to those of the sticky price models. Whereas the sticky price models tend to view exchange rate overshooting and exchange rate volatility as symptoms of some fundamental disequilibrium, the perspective taken in this paper is that such events are compatible with a world in which all markets clear continuously.

Both the model presented here and the sticky price models of the Dornbusch (1976) variety are consistent with the stylized facts concerning the behavior of exchange rates since the advent of managed floating. Which model is 'correct' is important from a policy wiswpoint because of their differing implications for the rcle of stabilization policy in the open economy. The issue will ultimately be solved empiricaliy. One key difference between the two models is that the model presented in the paper predicts that ant.ipated monetary shocks will not result in deviations from purchasing power parity or in exchange rate overshooting while, as demonstrated by Wilson $(1979)$, the sticky price models predict that anticipated monetary shocks will result in short-run deviations from purchasing power parity. Hence empirical tests concerining the impact of anticipated and unanticipated monetary shocks on purchasing power parity might be capable of discriminating between the two models.

\section{Referrimces}

Balussa, B., 1964, The purchasing power parity doctrine: A reappraisal, Journal of Political Ezentwony 72, 584-546.

Batre; R.J. 1977, Long-term contracting, sticky prices, and monetary policy, Journal of Nonetary Economirs 3, 305-316. 
Bilson, J.F.O., 1978, Rational expectations and the exchange rate, in: J.A. Frenkel and H.G. Johnson, eds., The economics of exchange rates: Selected studies (Addison-Wesley, Reading. MA) 75-96.

Bilson, J.F.O., 1979, Recent developments in monetary models of exchange rate determination. IMF Staff Papers 26, 201-223.

Blanchard, O.J., 1980, Wage indexing rules and the behavior of the economy, Journal of Political Economy 87, 798-815.

Buiter, W.H. and J. Eaton, 1980, Poliry decentralization and exchange rate management in interdependent economies, NBER working paper. no. 53 '.

Calvo, G.A. and C.A. Rodriguez, 1977, A model of exchange rate determination under currency substitution and ration:' expectations, Journal of Political Economy 85, 617-625.

Dornbusch, R., 1976, Expetations and exchange rate dynamics, Journal of Pollitical Economy $84,1161-1176$.

Fischer, S., 1977, Long-term: con'racts, rational expectations, and the optimal money supply rule, Journal of Political Economy 85, 191-206.

Fischer, S., 1980, Rational expectations and economic policy (University of Chicago, Chicago, IL).

Fleming, J.M., 1962, Domestic financial policies under fixed and under hoating exchange rates. IMF Staff Papers 9. 369-379.

Flood, R.P., 1977, Growth. prices, and the balance of payments, Canadian Journal of Economics 10, $193-207$.

Flood, R.P., 1979, An exarnple of exchange rate overshooting, Southern Journal of Economics $46,168-178$.

Frenkel, J.A., 1976, A monetary approach to the exchange rate. Scandinavian Journal of Economics 78, 200-224.

Frenkel, J.A., 1981a, The collapse of purchasing power parities during the 1970s, European Economic Review 16, 175-i65.

Frenkel, J.A., 1981b, Flexible exchange rates, prices, and the role of news: Lessons from the 1970's, Journal of Political Economy 89, 665-705.

Frenkel, J.A. and M. Mussa, 1980, Efficiency of foreign exchange markets and measures of turbulence, American Eonomic Review 70, 374-381.

Frenkel, J.A. and C.A. Rodriguez, 1980, Exchange rate dynamics and the overshooting hypethesis, Unpublisheit manuscript (University of Chicago. Chicago, IL).

Gray, J.A. 1976, Wage indexation: A macroeconomic approach, Journal of Monetary Economics 2, 221-235.

Gray, J.A., 1978, On index ation and contract length, Journal of Political Economy 86, 1-18.

lsard, P., 1977, How far can we push the law of one price, American Economic Review 67, 942948.

Isard, P., 1978, Exchange rate determination: A survey of popular views and recent models. Princeton Studies in International Finance, no. 42.

Kimbrough,, K.P., 1980, Real disturbances, the current account, and the monetary approach to the exchange rate, Unpublished manuscript (Duke University, Durham, NC).

Kravis, I.B and R.E. Lipsey, 1978, Price behavior in the light of balance of payments theories. Journal of International Economics 8, 193-246.

Meese, R. and K.J. Singleton, 1980, Rational expectations and the volatility of exchange rates, Unpublished manuscript, Board of Governors of the Federal Reserve System. Washington, DC and Carnegic-Mellon University, Pittsburgh. PA.

Mundell, R.A., 1963, Capital mobility and stabilization policy under fixed and flexible exchange rates, Canadian Journal of Economics and Political Science 29, 475-485.

Mussa, M., 1976, The exchange rate, the balance of payments and monetary and fiscal policy under a regime of controlled floating, Scandinavian Journal of Economics 78. 229-249.

Mussa, M... 1977, A dynamic theory of foreign exchange, in: M.J. Artis and A.R. Nobay, eds.. Studies of modern economic analysis (Basil Blackwell, Oxford) 121-143.

Mussa, M. 1979a, Empirical regularities in the behavior of exchange rates and theories of the foreign exchange market, in: Vol. 11 of the Carnegie-Rochester Conference Series on Public Policy, a supplementary series to the Jou nal of Monetary Economics. 957. 
Mursa, M. 1979b, A ritndel of exchange rate dynamics, Unpublished manuscript (University of Chicago, Chicago, ILi.

Nielaans, J. 1979. Exchange rate dynamics with stock/llow inceraction, Journal of Political 1"toxpomy 85, 1245-1257.

Oifwer, $L$., 1976, The purchasing power parity theory of exchange rates: A review article, IMF situll Papers 23, 1-61.

Saryent, T.J., 1979, Macroeconomic theory (Acsdemic Press, New York).

Taylor, J.B. 1980. Aggregate dynamics and staggered contracts, Journal of Folitical Economy 81. 1.23.

Waldo, D.G. 198I, Sticky nominal wages and the optimal employment ruie, Journal of Uonetary Econon ices 7, 339-353.

Wa liah. H.C. and J.A. Gray, 1980, Stabilization policy and vicious and virtuous circles, in: J.S. Thipman and C.P. Mindleberger, eds., Flexible exchange rates and the balance of payments North-Holland, Amsiterdam) 49-65.

Wit an. C.A. 1979. Anticipated shocks and exchange rate dynamics, Journal of Political feonomy 87. 639-647. 